\title{
EN EL CENTENARIO DE LA ACADEMIA DE BELLAS ARTES DE ESPAÑA EN ROMA
}

\author{
María Angeles Alonso Sánchez
}

Fue hace exactamente cien años, el día 25 de abril de 1874, cuando el actual edificio de la Academia de Bellas Artes de España en Roma abrió sus puertas para que en ella comenzaran a vivir los pensionados españoles. Un decreto de pocos meses antes había determinado la creación de la Academia española en la Ciudad Eterna. Esta fecha, 3 de agosto de 1873, y la anteriormente citada, aireadas pomposamente por los políticos de su tiempo e incluso una de ellas esculpida (1) en la lápida de mármol que aún hoy se conserva en el claustro de la izquierda del viejo convento, han provocado durante los últimos meses del pasado año de 1973 una serie de artículos en periódicos y revistas y de actos conmemorativos del "centenario de la Academia de España en Roma». Así se decía en todos ellos, ignorando olímpicamente la vida de la Academia durante el período precedente al establecimiento en el actual edificio.

Confieso que la lectura de tales artículos y noticias despertó en mí (dedicada desde hace años a otros campos de la investigación) el propósito de escribir algo, exhumando los documentos que sirvieron de base a mi tesis doctoral y saliendo así por los fueros del que fue verdaderamente el primer director de pensionados, el tan injustamente olvidado, Francisco Preciado de la Vega. Y por la auténtica primera promoción de pensionados, la que llegó a Roma el día de Jueves Santo de 1747.

Porque yo entiendo que la Academia Española comenzó a existir no cuando el antiguo convento de los Franciscanos se transformó, por

(1) En dicha lápida se lee: «Esta Real Academia fue fundada por el señor don Emilio Castelar, el cual realizó los trabajos que dieron por resultado el Decreto de creación de fecha 3 de agosto de 1873 y el de 23 de enero del año 1881...» 
R.O. de Alfonso XII, en residencia de los Pensionados, sino cuando a Roma llegó la primera promoción de ellos. La Academia no es el edificio, sino los artistas que la integran, como lo prueba el hecho de que más de una Academia setecentesca no tuvo sede común. ¿Qué importa que los pensionados vivieran separados si realmente estaban organizados como grupo, dependiente de la Academia de S. Fernando de Madrid, gobernados según las instrucciones que de allí emanaban (2), y bajo la tutela de un Director que tenía conciencia de desempeñar el mismo papel que el Director de la Academia de Francia? Bien lamentaba éste que no hubiera un edificio común, pero la miopía de los de S. Fernando impidió que se realizasen sus deseos. Durante los treinta años en los que ejerció su cargo de Director de Pensionados no dejó de suspirar por reunir a éstos en una casa, sin que nunca llegara a conseguirlo. Ya el 7 de febrero de 1759 escribía encareciendo la conveniencia de que los pensionados viviesen en unas habitaciones que habían quedado libres debajo de las que él ocupaba «para tenerlos más unidos y a la vista y por ahorrar gastos». En la Junta Particular (1) de la Academia de S. Fernando el día 24 de abril de 1760 se daba cuenta de otra comunicación del Director de Roma en la que manifestaba sus desos de que todos viviesen juntos «para mejor celarlos». En diciembre de 1761 nuevamente hablaba Preciado en una carta de la necesidad de encontrar un edificio para Academia de España en Roma. En julio del 62 se lamentaba de que por no tener casa común no tenían los pensionados sitios donde guardar los instrumentos de trabajo. En 1778, cuando la Academia pensó en reanudar la costumbre de enviar Pensionados a Roma (2), escribía Preciado insistiendo en su viejo deseo: «Sería siempre lo mejor que todos estuviéramos en una casa, a modo de la Academia de Francia». E incluso sugería la idea de que esta casa se costease con algunas «pensiones» puestas sobre los Obispados (3). Pero tampoco entonces cuajó la idea.

(2) Este es el criterio que preside para establecer la fecha de fundación de otras Academias. Cfr. Henry Lapauze: Histoire de l'Academie de France a Rome. París, 1924; T. I.

(1) Libro de Juntas Particulares, 1760. Archivo de la Academia de San Fernando. Madrid.

(2) Dicha costumbre se había interrumpido oficialmente en 1764.

(3) En carta a don Antonio Ponz de fecha 20 de agosto de 1778 afirma Preciado: «El señor Muñino, que está muy informado de todo, pudiera contribuir mucho a esta nueva erección, de modo que fuese decorosa a la nación y más útil, sin dispendio de esa Ácademia, poniendo algunas pensiones sobre los Obispados, así como ésta de Francia las tiene sobre varias Abadias, de modo que mantiene doce jóvenes y el gasto viene a ser de 6.000 escudos, que a poco por Obispado sería 


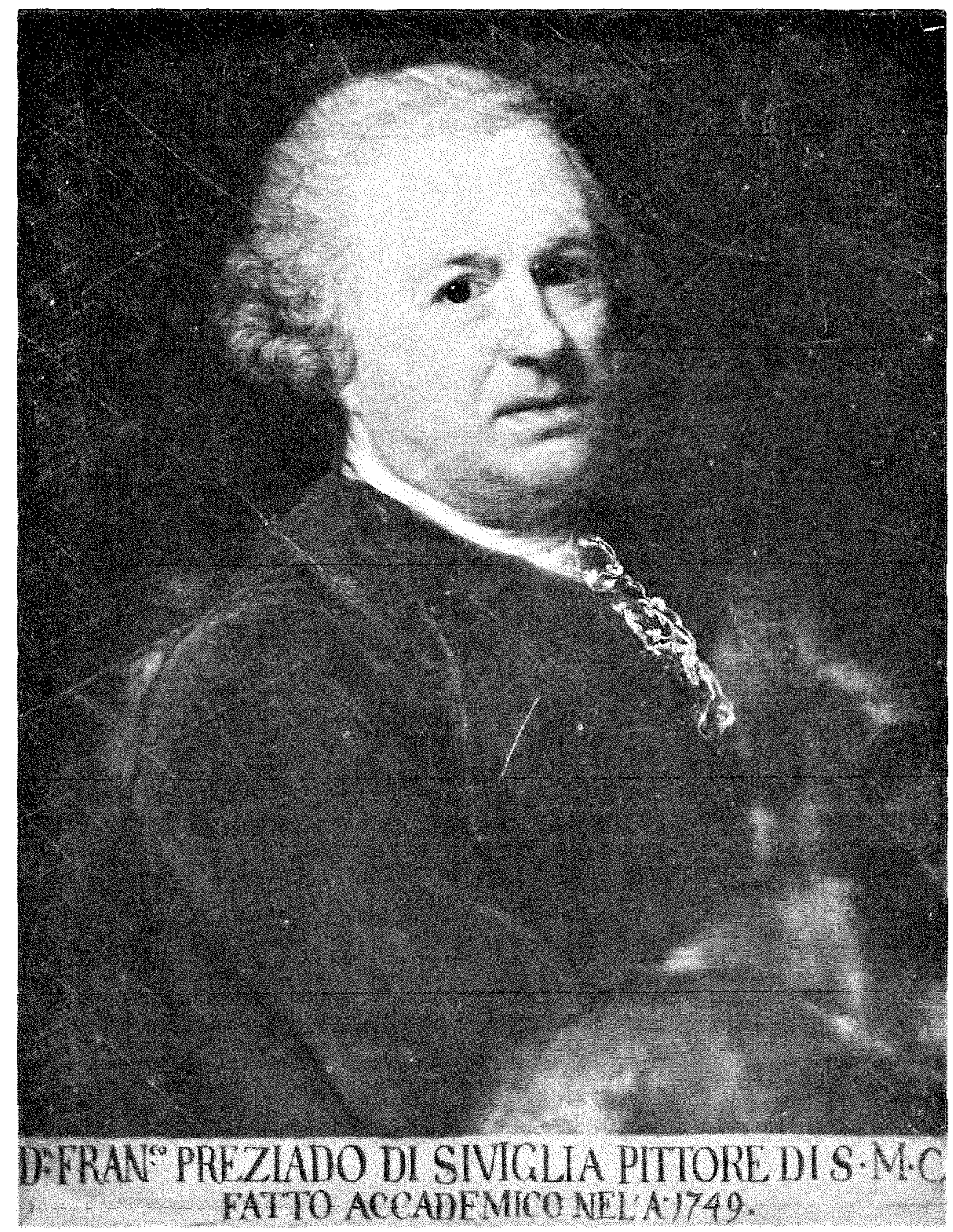

Academia de S. Lucas - Roma. 


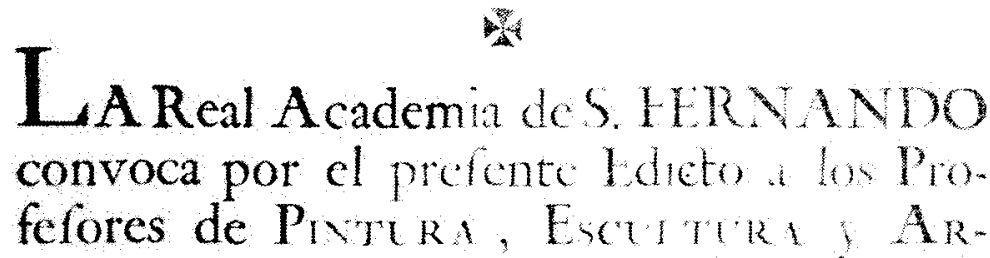
Quitectura naturales de citor Royno, a la opoficion de quatro Penfiones que refultam vacantes en Roma, una de PNTT'RA, otra de Escultura y dos de AregtTecter 1, defde eldiade la fecha de cite Edicto hatta cl 20. de Mayo de ette prefente ano, con las prevenciones figuicntes.

I.

Han de entregar dentro del termino exprefado al secretario de la Acadomia fus Fees de Bautimo.

2.

En la Junta Generalle les repartion afuntos ate the de trabajar precilament cerratos y obtervados en la Acadomia, en la forma y mode ue feles prelerta

3.

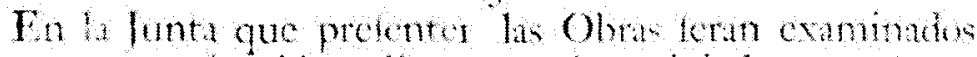
y preguntadon fobr ellas a voluntad de low retpetwos Directures, para que gradu lo el morto, he propongan a S.M. Jo mas dignos.

Tparaque llegue à noticia de todos los que preicudan obtener eftas Penfiones, acordo la Academia que fe publique elprefente ldiclo. Madrad a 20 . de dirit de $1-58$.

D. Ignacio de Hermofilla y Sandoval. 


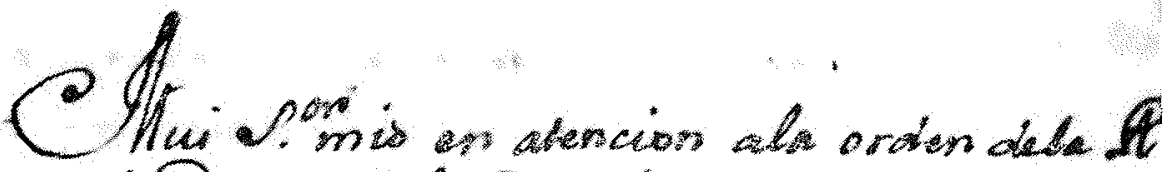

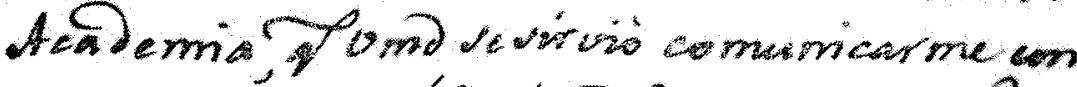

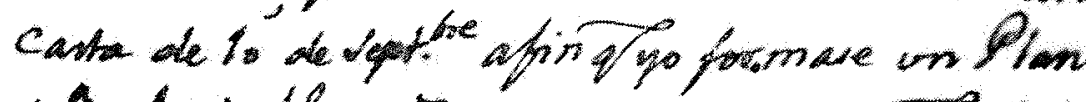

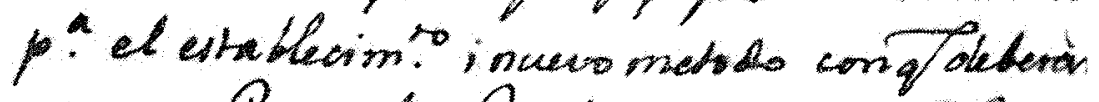
utar en Doma los Densionado de Sing que ín. viarin en Defanie, mas aplicados itopres ai ami com- alos demia Directores, of meie

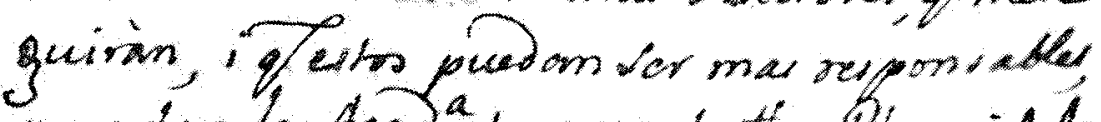
y pooter la Acada tomar de atho Jian, dela

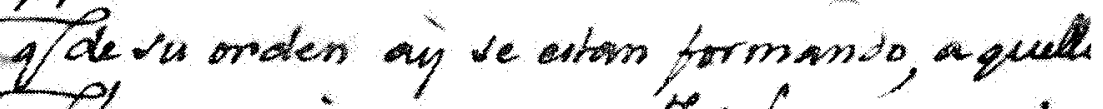

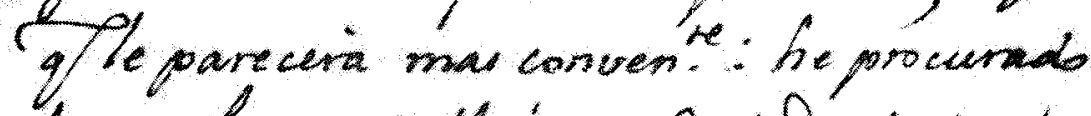
formanto con reflesion al erbolo, vituacion en oy re halle la Academix is temito mano delvomphansul de Roda comóloms me ha insinualo.

Mo procune pormank Sabor ponimar como

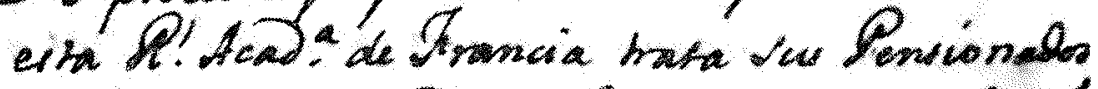

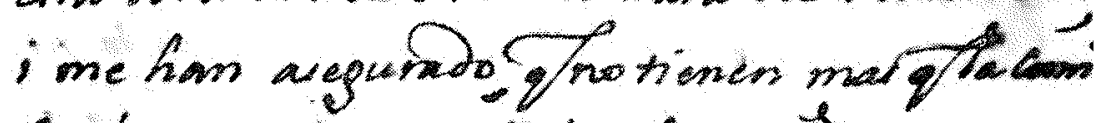

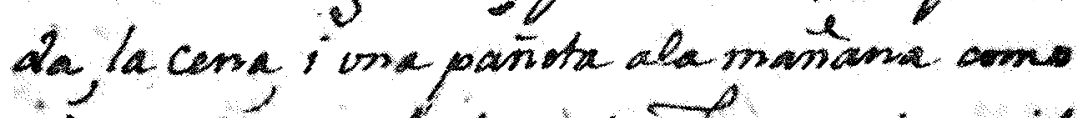
in' Lucrito en elpian, sin tay quien caide de areantes sus quator (awn' no fuese ma que

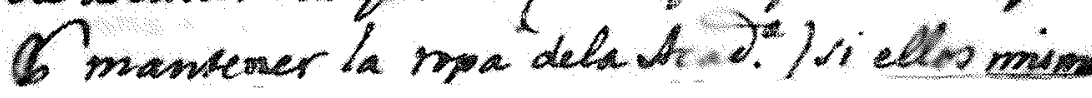

Carta de Preciado a D. Ignacio de Hermosilla en fecha 2-II-1764 - Fol. 1. 
Francisco Preciado de la Vega había llegado a Roma en 1732. Con sus veinte años aún no cumplidos, ávido de encajarse en el ambiente artístico romano, debió quedar deslumbrado ante el panorama que ofrecía aquella ciudad "agitada y al mismo tiempo tranquila, refinada y difícil, y a la vez solemne y familiar» (1), donde quien lo desease podía vivir por su cuenta, empleando al tiempo según el propio gusto, pero donde no era difícil - tampoco a los extranjeros- engranarse en la sociedad, frecuentando los numerosos salones y las muchas academias donde se discutían las ideas y los problemas más actuales.

Preciado era andaluz y poseía una personalidad realmente compleja: pintor, historiador, teorizador, poeta... En verdad que tuvo más de erudito que de artista, y así dicen más sus obras en prosa o en verso que sus cuadros diseminados por las iglesias y galerías de Roma o enterrados entre el polvo de los depósitos de la Academia de S. Fernando. Sin embargo, es evidente $-y$ ahí me parece que radica su importanciaque ejerció un poderoso influjo en la preparación del neoclasicismo español y que fue uno de los instrumentos más eficaces no sólo para la creación de la Real Academia de S. Fernando (y su proyección en Roma), sino también para que entrase ésta en los cauces de la pintura europea del siglo. Pero también estos méritos, lo mismo que toda su figura, han sido ignorados por los historiadores del arte.

El pintor andaluz fue a Roma y se mantuvo alli a sus expensas durante los primeros siete años. En este tiempo fue discípulo de Sebastián Conca (2) y frecuentó la Academia de S. Lucas (3). En el año 1739 la Academia de S. Lucas le otorgó un premio (4) y consecuencia de esta distinción fue la concesión hecha, en el año siguiente, por el Rey de España, de una pensión de quinientos ducados.

Estaba entonces cuajándose la fundación de la Academia de S. Fernando (5) y el papel de Preciado fue de gran importancia en cuanto que remitió desde Italia los estatutos de la de S. Lucas y de la de

tolerable y caritativo para un fin que redunda en beneficio del Reino y de todas las manufacturas aun mecánicas que tienen su raíz en el dibujo.»

(1) Lavagnino: Il Settecento a Roma. Roma, 1959.

(2) Nació este pintor en Gaeta hacia 1680 y murió en Nápoles en 1764. A pesar de la superficialidad de sus obras, fue pintor muy apreciado en su siglo, llegando a ser nombrado Caballero de Clemente XI y profesor de la Academia de S. Lucas.

(3) La Academia de S. Lucas había surgido en el siglo Xvi de una antigua compañía de pintores. Sus primeros estatutos son de 1715, dados por Clemente XI.

(4) La distinción que se le otorgó fue el segundo premio de la primera clase de pintura. Cfr. Delle lodi delle belli arti, orazioni e componimenti poetici detti in Campidoglio, año 1739, Arch. Ac. S. Lucas.

(5) El 13 de julio de 1744 admitió Felipe V el proyecto. 
Francia, más toda una serie de datos a cual más provechoso. En Preciado y en Aróstegui (Agente del Rey en Roma durante esos años), tuvieron los Académicos una ventana abierta por la que llegaban noticias, libros e incluso reproducciones artísticas. Poseemos la lista de los moldes que en 1745 se encargaron a Aróstegui para que los enviase de Roma y Florencia. Son, en su mayor parte, obras clásicas griegas y romanas y algunas más de Miguel Angel. Juntamente se encargaban una serie de libros de perspectiva, geometría y demás materias auxiliares. Esta remesa constituyó la primera piedra del actual museo de la Academia de S. Fernando y de su biblioteca (1).

Así estaban las cosas cuando en diciembre de 1745, respondiendo a las exigencias del ambiente $\mathrm{y}$, sobre todo, a los deseos y sugerencias de Antonio González (2), Pablo Pernichero y Juan Bautista de la Peña (estos dos últimos recién llegados de Italia), Felipe V ordenó a la Junta de la Academia de S. Fernando que determinase las condiciones y cualidades que deberían tener los pensionados que la monarquía española enviase a Roma, así como el tiempo que habían de permanecer allí (3). La Real Orden estaba dirigida a don Fernando Treviño, Viceprotector de la Academia, que se encontraba aún en los tiempos de la Junta Preparatoria. En dicha Real Orden se expresaba también el decidido propósito del Rey de enviar Pensionados a Roma con cierta regularidad, se establecía la cantidad de quinientos ducados como pensión para los más adelantados y cuatrocientos para los demás, con opción a las vacantes, señalándose también veinticinco doblones para cada uno en concepto de gastos de viaje.

A fin de que la Academia tuviese noticia de los adelantos que dichos pensionados realizaban, ordenaba Su Majestad que cada uno enviase a la Academia "una pieza de su respectivo arte» y "para que en la ejecución no haya fraude» se ordenaba a la Junta que determinase y participase al auditor don Alfonso Clemente de Aróstegui (4) que tomase las debidas precauciones a fin de que todos y cada uno cumpliesen con

(1) «Don Miguel de Herrero ha puesto en mis manos un ejemplar impreso de los estatutos de la Academia de S. Lucas de Roma y un resumen del método con que se gobierna la Academia de Francia en Roma, los cuales le ha remitido el pintor Francisco Preciado». Libro de Actas, año 1744. Archivo de la Acad. de S. Fernando.

(2) Había estado en París, Roma y otras ciudades de Italia. A su regreso lo nombró Felipe $\mathrm{V}$ director de los estudios de la Junta Preparatoria.

(3) R. O. de 2 de diciembre de 1745.

(4) Era entonces Aróstegui Prelado Doméstico de S. S. y Auditor honorario de la Sacra Rota por el Consejo Real de Castilla y desempeñó interinamente el cargo de representante del Rey en Roma durante el año 1747. 
sus respectivas obligaciones. Es notable la insistencia con que se encarece el deseo del Rey de que los pensionados aprovechen el tiempo y cumplan con sus obligaciones, prueba de la importancia que se concedía al envío de éstos. Y así no duda en volver a ordenar en la misma R.O.: $« \ldots$ a este Ministro tiene S.M. mandado que intervenga todas las libranzas de estos sueldos y que por ningún caso les dé paso si los interesados no han cumplido a su satisfacción en todo lo respectivo a las tres artes, en el tiempo que comprende cada libranza». Se determina también que el fondo del que han de salir estos sueldos es el producto de correos de España en Roma, si bien esta disposición tendrá vigencia durante pocos años (1).

Corría el mes de febrero de 1746 cuando tuvo lugar la oposición para proveer las plazas de pensionados en Roma. Las plazas creadas eran seis: dos para pintores, dos para escultores y dos para arquitectos, mas como ya Francisco Preciado y el escultor Francisco Vergara (2) disfrutaban sendas pensiones, aquéllas quedaban reducidas a cuatro a la hora de sacarlas a concurso: una de pintor, otra de escultor y dos para arquitectos. No sin trabajo se consiguió hallar a los concursantes, pero al fin tuvieron lugar las pruebas y resultaron vencedores: Antonio González Velázquez (pintor), Francisco Gutiérrez (escultor) y Juan de Villanueva y Alejandro González Velázquez (arquitectos). Los dos últimos por diversos motivos renunciaron a la pensión y en su lugar fueron elegidos Miguel Fernández y José de Hermosilla.

No llegaron nuestros pensionados a Roma hasta el día de Jueves Santo de 1747, después de haber invertido en su viaje nada menos que cincuenta y cuatro días y haber pasado mil aventuras y contratiempos, a causa de los cuales se vieron obligados a pedir una nueva ayuda económica, pues habían tenido que vender incluso sus ropas personales para llegar al fin de la meta (3).

(1) En 1757 se decidió que la Academia de S. Fernando corriera con sus gastos, tal como lo ordenaban sus estatutos, si bien se determinó que el pago se hicierá mediante la Tesorería de Correos, a fin de que no se cargase a la Academia con los gastos de "cambio y conducción".

(2) Natural de Valencia, había comenzado sus estudios en su tierra en la escuela de dibujo de Evaristo Muñoz. Frecuentó después la Academia en época de la Junta Preparatoria, haciendo algunas estatuas, que fueron bien estimadas, para la iglesia de S. Ildefonso. Como consecuencia, se le concedió una pensión para pasar a Roma, donde estudió escultura bajo la dirección de Felipe del Valle.

(3) «En Liorna nos vimos empeñados y sin alivio para seguir el viaje, y así precisados a vender toda la ropa para subsistir, y a no haber tenido la fortuna de encontrar un paisano que pasaba a Nápoles, quien viendo el deplorable estado en que nos hallábamos nos ofreció suplirnos, con el con qué de que aquí le habíamos de satisfacer". Carta a don Fernando Treviño. Archivo de la Acad. de S. Fer. Leg. 48. 
Pronto organizó Aróstegui el plan de trabajo de los pensionados. Sabemos que en el mes de julio frecuentaban ya estudios y Academias con gran aprovechamiento (1). Antonio González Velázquez asistía al taller de Conrado Giaquinto, cuyo estilo tanto asimiló. Francisco Gutiérrez frecuentaba en la Academia de San Lucas las lecciones de Maini, empapándose de este gusto por lo monumental que habia de transparentar su celebrada Cibeles. Fernández y Hermosilla tenían por maestro al caballero Fuga que -en frase de Aróstegui al dar cuenta a la Academia «es uno de los más acreditados en la profesión y con quien espero se podrán aprovechar». Vergara continuaba trabajando junto al acreditado Felipe del Valle (2), y Francisco Preciado, plenamente encajado ya en los ambientes artísticos romanos (desde su llegada a Roma había asistido con regularidad a la Academia de San Lucas), se empapaba en el tardo barroco rapolitano, a través de las enseñanzas de Conca, caracterizadas por un jordanismo no exento de ciertas tendencias hacia el clasicismo maratesco.

Los pensionados vivían aislados en distintas posadas y con bastante independencia entre sí. Aróstegui los reunía en su casa los domingos y allí, en su presencia, les hacía ejecutar alguna obra para poder dar cuenta de sus progresos a la Academia.

El día 12 de abril de 1752 tuvo lugar el reconocimiento oficial de la Academia de San Fernando por parte del Rey Fernando VI, y una vez llevados a cabo los trabajos de reorganización de la ilustre corporación -ahora bajo la protección de Carvajal-, los académicos emprendieron con verdadero interés la reglamentación de los estudios en Roma. Tres años emplearon (1754-1757) en la elaboración de un reglamento en el que quedase clara y terminantemente dispuesto todo lo concerniente a las pensiones en Roma para pintores, escultores y arquitectos. Según este reglamento, aprobado y puesto en vigor el año 1757, se creaba el cargo de Director de Pensionados y éste vino a recaer sobre el pintor sevillano Francisco Preciado de la Vega, que era, sin duda, el que gozaba en aquella ciudad del mayor prestigio. Se unía a esto la circunstancia de haberse casado en 1750 con la italiana Catalina Cherubi-

(1) Carta de Aróstegui a don Fernando Treviño en fecha 20 de julio. Arch. Academia S. Fernando. Leg. 50.

(2) Escultor de gran prestigio en Roma, fue nombrado Príncipe de la Academia de S. Lucas en el año 1752. 
ni (3), razón por la cual era de prever que no volvería fácilmente a España.

Recibió Preciado el nombramiento con alegría y gratitud, pero juzgó enseguida que el estipendio que se le asignaba era muy corto. El ejemplo del fausto con que vivía el Director de la Academia de Francia le había hecho concebir la idea de que algo semejante le tocaría en suerte y ahora veía con disgusto que solamente se le aumentaban cien ducados al año, sobre los quinientos que ya gozaba como pensionado. Su carta a don Ricardo Wall en fecha 14 de junio (1), que quiere ser expresión de gratitud, lo es de queja por el «tenue salario», que juzgaba totalmente insuficiente para vivir con la dignidad que el cargo requería. Abonaba su causa con una serie de razones no muy oportunas y que más bien exasperaron los ánimos de los académicos en lugar de atraerlos a su favor. Y por si eran poco todas estas quejas y pretensiones, finalizaba Preciado su memorial reclamando "ciertas mesnadas» que se le habían dejado de pagar en tiempo de Felipe V.

Para colmo de males, con la carta de Preciado llegó a la Academia un memorial escrito por el escultor Fracisco de Vergara haciendo presentes otras varias pretensiones. Llevaba Vergara como pensionado en Roma algo más de doce años y la Academia había acordado en la Junta Particular del día 9 de mayo que cesaran en sus pensiones y se restituyeran al reino tanto Vergara como los otros dos pensionados que aún quedaban en Roma (Miguel Fernández y Francisco Gutiérrez). Pero Francisco Vergara que se hallaba trabajando las estatuas que le habían sido encargadas en 1754 por el Cabildo de la Catedral de Cuenca, se creyó en el derecho de pedir que se le prorrogase la pensión a fin de poder llevar a término su compromiso, e incluso llegó a sugerir a la Academia que no nombrase Director de Pensionados de Escultura, alegando que se lo había prometido el propio Carvajal. Mas los académicos, a los que no parecía ni medio bien que sus pensionados, enviados al extranjero con tanto esfuerzo económico de España, a fin de que de allí trajeran a los ambientes españoles una corriente renovadora, se quedaran por aquellas tierras sin dar ningún fruto para su patria, se negaron a ello, otorgándole solamente el permiso para permanecer en Roma otros dos

(3) Fue Catalina Cherubini artista notable, especialmente en miniatura. La Academia de S. Fernando le concedió una pensión en el año 1761 y la nombró académica de mérito a consecuencia de haber enviado un cuadro copia de «La Justicia y la Paz», de Ciro Ferri. Fue también académica de S. Lucas.

(1) Con la mismá fecha escribe otra carta, casi igual a ésta, a don Ignacio de Hermosilla. 
años ( $\operatorname{cin}$ pensión), a fin de que terminase sus obras, pasados los cuales debería restituirse al Reino, en cuyo único caso se le pagarían los mil quinientos reales que la ley determinaba como ayuda de costas (2).

El acta de esta Junta particular en la que se examinaron las pretensiones de Preciado y Vergara expresa con gran elocuencia cuánto desagrado causaron éstas en los académicos. Ignacio de Hermosilla fue el encargado de comunicar a Preciado y a Vergara las decisiones de la Junta. Lo hizo en fecha 12 de agosto y en términos bastante más suaves que los expresados en aquélla. Posiblemente el tiempo transcurrido (casi un mes) había servido de lenitivo a la indignación de los académicos. De todos modos, la negativa es clara y no deja lugar a dudas. Bien lo entendió Francisco Preciado quien, ante la alternativa de aceptar o no el cargo de Director, contestó rendido y sumiso aceptando y poniéndose incondicionalmente a las órdenes de la Academia.

Superado este desafortunado lance, y confirmado el nombramiento de Preciado como Director de Pensionados, se dispuso éste a ejercer su cargo con la nueva promoción de pensionados que realizaron sus oposiciones en el año 1758. Eran éstos: por la pintura, Domingo Alvarez y José del Castillo; por la escultura, Isidro Carnicero y Antonio Primo, y por la arquitectura, Juan de Villanueva y Domingo Lois Monteagudo.

Tras estos artistas habrían de venir otros, hasta completar el número de treinta que constituye el cupo de pensionados que Preciado tuvo a su cargo en los treinta y un años, durante los cuales ejerció su dirección. De ellos, diecisiete habían ido a Roma en calidad de pensionados ordinarios, es decir, después de haber realizado las pruebas de selección preceptuadas por la Academia. Los trece restantes fueron pensionados extraordinarios. Estos treinta pensionados correspondían: a la pintura, quince; a escultura, nueve, y a arquitectura, seis. En realidad, la desproporción en el reparto se debe a los pensionados extraordinarios ya que las pensiones ordinarias eran siempre distribuidas a las distintas artes en el mismo número.

Los últimos pensionados que Preciado tuvo a su cargo regresaron a España a finales de 1785. Y las dificultades económicas obligaron a la Academia a suspender temporalmente el envío de pensionados. Cuatro años después, el 17 de julio de 1789, fallecía en Roma, honrado y elogiado en los ambientes artísticos romanos, Francisco Preciado de

(2) Vergara no llegó a regresar, pues murió repentinamente en Roma el día 30 de junio de 1761, a la edad de cuarenta y ocho años. Cfr. Ceán Bermúdez: Diccionario de los más ilustres profesores de Bellas Artes, en la voz: Vergara. 
la Vega. En cambio, los académicos de San Fernando se limitaron a consignar el hecho en el libro de actas, donde se lee: "Di cuenta de haber fallecido don Francisco Preciado, Director de Pensionados, en Roma» (1). Ni una palabra más acerca de este hombre que había sido una piedra fundamental en la fundación de la Academia de San Fernando. Ni una alabanza para el que, al morir, cerraba la primera etapa (y la más difícil) de la Academia de Bellas Artes de España en Roma. Comanzaban los injustos olvidos.

(1) Junta Partícular del día 9 de agosto de 1789. Archivo de la Academia de S. Fernando. 